\title{
PENGARUH KEPEMIMPINAN KEPALA SEKOLAH DAN BUDAYA ORGANISASI TERHADAP PROFESIONALISME GURU
}

\section{THE PRINCIPAL LEADERSHIP AND ORGANIZATION CULTURE'S INFLUENCES TOWARD TEACHER PROFESSIONALISM}

EUIS EVICASARI

SMA Negeri 72 Jakarta

\section{Received: May 06, 2021 \\ Revised: May 10, 2021 \\ Accepted: May 17, 2021}

\begin{abstract}
During Covid-19 pandemic, a teacher is required to adapt. Teacher professionalism requires leaders who can direct and develop in accordance with organizational goals and a conducive working atmosphere. This research to determine the influence of principal leadership and organization culture to teacher professionalism in a public high school. This research is quantitative. Population this study is teachers in 116 high schools, then using the Cluster Sampling 11 schools obtained the population in this study. Total population is 169 teachers. The samples conducted by using the formula Slovin, collected by questionnaire and analyzed with path analysis. The result that leadership have a significantly effecttiveness on the teacher professionalism of 37,4\%, the organization culture have a significantly effectiviness on the teacher professionalism of $29,6 \%$, and leadership have a significantly effecttiveness on the organization culture of $17,2 \%$. It can be concluded that leadership and organizational culture have a positive effect on teacher professionalism
\end{abstract}

Abstrak. Di masa pandemi Covid-19 seorang guru di tuntut untuk bisa beradaptasi dengan perubahan yang begitu cepat dan kompleks. Profesionalisme guru membutuhkan pemimpin yang bisa membimbing dan memajukan usaha-usaha bawahannya sesuai dengan sasaran organisasi serta suasana kerja yang kondusif yang dapat memberikan rasa nyaman dalam bekerja sehingga sangat berpengaruh pada kualitas kerja guru. Penelitian ini bertujuan untuk mengetahui dan menelaah pengaruh signifikan kepemimpinan kepala sekolah dan budaya organisasi terhadap profesionalisme guru di SMA Negeri Daerah Khusus Ibukota Jakarta baik secara parsial ataupun simultan. Jenis penelitian yaitu penelitian kuantitatif. Populasipenelitian iniyaitu gurudiSMA Negeri Daerah Khusus Ibukota Jakarta yang terdiri dari 116 sekolah selanjutnya dengan menggunakan Cluster Sampling didapat 11 sekolah yang menjadi populasi dalam penelitian ini. Populasi dalam penelitian ini berjumlah 169 guru. Penentuan sampel dilaksanakan dengan menggunakan rumus Slovin. Pengumpulan data menggunakan kuisioner. Analisis data menggunakan analisis jalur (Path Analysis). Penelitian ini untuk mengetahui seberapa besar pengaruh kepemimpinan kepala sekolah dan budaya organisasi terhadap profesionalisme guru. Hasil penelitian ini menunjukkan bahwa kepemimpinan kepala sekolah berpengaruh signifikan terhadap profesionalisme guru sebesar 37,4\%. Budaya organisasi berpengaruh signifikan terhadap profesionalisme guru sebesar $29,6 \%$. Kepemimpinan kepala sekolah berpengaruh signifikan terhadap budaya organisasi sebesar 17,2\%. Berdasarkan hasil bisa diambil kesimpulan yaitu kepemimpinan kepala sekolah dan budaya organisasi berpengaruh langsung positif terhadap profesionalisme guru

Keywords: Leadership, organization culture, teacher professionalism

Kata kunci: Kepemimpinan, budaya organisasi, profesionalisme guru

${ }^{*}$ ) Corresponding Author: euisevica72@gmail.com

How to Cite: Evicasati, E. (2021). Pengaruh Kepemimpinan Kepala Sekolah Dan Budaya Organisasi Terhadap Profesionalisme Guru. Jurnal Lingkar Mutu Pendidikan, 18 (1), 68-72. https://doi.org/10.54124/jlmp.v18i1.17

\section{PENDAHULUAN}

Guru profesional ialah guru yang mempunyai keahlian yang menjadi syarat untuk melaksanakan tugas pendidikan dan pengajaran secara maksimal. Menurut Undang-Undang No. 14 Tahun 2005 tentang Guru dan Dosen menyatakan bahwa "Guru profesional ialah mata pencaharian atau pekerjaan yang dikerjakan seseorang yang menjadi sumber pendapatan dan membutuhkan keahlian, kemahiran atau kecakapan dengan persyaratan akademik, kompetensi dan kewajiban didalamnya".

Pemerintah telah melakukan upaya dalam peningkatan profesionalisme guru yang maksimal 
antara lain adalah program sertifikasi guru dengan meningkatkan kesejahteraan guru yang sejalan dengan tuntutan peningkatan profesionalisme kerja guru. Sebagai agen pembelajaran yang menguasai kompetensi dan mempunyai kualifikasi akademik adalah salah satu syarat bagi guru sebagai pendidik profesional.

Kepemimpinan dan usaha-usaha pemberdayaan semua sumber daya adalah tugas kepemimpinan yang sangat penting. Hal ini diperkuat melalui hasil penelitian yang dilaksanakan oleh Ismail yang menyebutkan bahwa kepemimpinan kepala sekolah menunjukkan pengaruh yang cukup kuat terhadap motivasi kerja guru di Sekolah Dasar Negeri Kecamatan Ngamprah dengan pengaruh yang signifikan (Ismail, 2017: 60-69).

Kualitas kerja guru sangat berpengaruh pada situasi kerja yang mendukung dan dapat memberikan rasa tenteram saat bekerja. Berdasarkan pendapat dan dari beberapa penelitian yang telah diuraikan maka dilakukanlah penelitian tentang pengaruh kepemimpinan kepala sekolah dan budaya organisasi sekolah terhadap profesionalisme guru di saat pandemi Covid-19 yang dilakukan di Daerah Khusus Ibukota Jakarta yang terdiri dari sebelas (11) wilayah dari lima (5) kota dan satu (1) kabupaten.

Profesional menurut Anwar mengarah kepada seseorang yang menyandang satu pekerjaan atau mengenai penampilan seseorang dalam mewujudkan kinerja sesuai dengan pekerjaannya (Anwar, 2018: 22-23). Profesional mengarah pada suatu kegiatan yang dilakukan seseorang dengan keterampilan yang khusus.

Guru yang profesional menurut Kunandar seharusnya dapat mengemban dan melakukan kewajiban yang diberikan kepada peserta didik, orangtua, masyarakat, bangsa dan negara serta agamanya (Kunandar, 2011: 47). Pengajar yang kompeten akan tercermin dalam mengimplementasikan pekerjaab yang diberikan kepadanya dan ditandai dengan kemampuannya pada bidang materi maupun metode.

Menurut Tim Dosen UPI cara mempengaruhi kegiatan dari seseorang maupun kelompok dalam mencapai tujuan pada situasi atau kondisi tertentu disebut kepemimpinan (Dosen, 2008: 125).

Organisasi pendidikan adalah tujuan yang harus dicapai oleh kepala sekolah. Oleh sebab itu, kepala sekolah harus menunjukkan sikap adil dan objektif serta memiliki jarak yang sama dengan para anggotanya dalam memberikan pelayanan pendidikan (Dagli \& Akyol, 2019: 37). Guru yang memiliki usia yang matang dan berpengalaman biasanya memiliki komitmen organisasi yang tinggi daripada yang lain.

\section{METODE PENELITIAN}

Tempat penelitian dilaksanakan di SMA Negeri DKI Jakarta selama bulan Oktober sampai Desember 2020. Subjek penelitian dilakukan di SMA Negeri Provinsi DKI Jakarta yang terdiri dari 117 sekolah, dan selanjtnya dengan teknik Cluster Random Sampling diperoleh 11 sekolah dengan jumlah 169 guru yang yang mewakili wilayah di DKI Jakarta. Jenis penelitian adalah penelitian kuantitatif. Teknik Proporsional Random Sampling ialah teknik yang dilakukan dalam mengambil sampel dari populasi penelitian ini dengan menggunakan 5 (lima) skala yang mengacu pada skala Likert. Kemudian sampel ditentukan dengan menggunakan rumus Slovin.

Pearson Product Moment adalah metode korelasi yang dipakai dalam melakukan teknik uji validitas pada penelitian ini. Butir instrumen yang valid selanjutnya dihitung reliabilitasnya memakai rumus Cronbach Alpha. Analisis jalur (Path Analysis) dipakai dalam menganalisis data, sedangkan uji Kolmogorov Smirnov dipakai untuk menghitung uji normalitas.

\section{HASIL DAN PEMBAHASAN}

Variabel profesionalisme guru memiliki nilai maksimum 145 dan minimum 72, serta range (rentang) dengan nilai 73. Hasil hitungan statistik didapatkan pula nilai mean (rata-rata) sebesar 113,14; dengan standar deviasi (simpangan baku) sebesar 13,848; median (nilai tengah) sebesar 112,00; mode sebesar 107 dan varians dengan nilai 191,754.

Disribusi frekuensi diperoleh dari 169 sampel dapat diklasifikasikan dalam 9 kelompok, pada kelas interval nilai tertinggi berada pada rentang 108-116 (28\%) dan diikuti dengan kelas interval 99-107 (21\%), sementara nilai terkecil berada pada rentang $72-80$ yaitu sebesar $1 \%$ dan $2 \%$ untuk rentang 144-152. Data frekuensi dapat digambarkan sebagai berikut: 


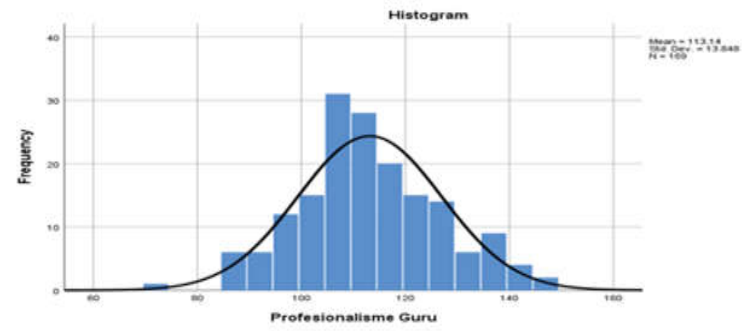

Gambar 1. Grafik Histogram Variabel Pofesionalisme Guru $\left(\mathrm{X}_{3}\right)$

Deskripsi data dari variabel kepemimpinan kepala sekolah memiliki nilai maksimum 145 dan miminum 66, serta range (rentang) dengan nilai 79. Hasil hitungan statistik didapatkan pula nilai mean (rata-rata) sebesar 114,15; dengan standar deviasi (simpangan baku) sebesar 14,167; median (nilai tengah) sebesar 114,00; mode sebesar 106 dan varians dengan nilai 200,710.

Distribusi frekuensi dari dari variabel kepemimpinan kepala sekolah dengan 169 sampel dapat diklasifikasikan dalam 9 kelompok. Pada kelas interval nilai tertinggi berada pada rentang 111-119 (30\%) dan diikuti dengan kelas interval 102-110 (22\%), sementara nilai terkecil berada pada rentang 66-74 dan 75-83 yaitu masing-masing sebesar 1\%. Data frekuensi dapat digambarkan sebagai berikut:

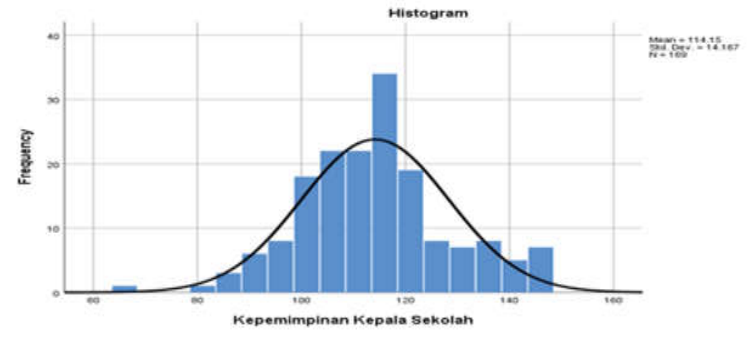

Gambar 2. Histogram Variabel Kepemimpinan Kepala Sekolah $\left(\mathrm{X}_{1}\right)$

Deskripsi data budaya organisasi memiliki nilai maksimum 145 dan miminum 78, serta range (rentang) dengan nilai 67. Hasil hitungan statistik didapatkan pula nilai mean (rata-rata) sebesar 114,22; dengan standar deviasi (simpangan baku) sebesar 13,105; median (nilai tengah) sebesar 115,00; mode sebesar 115 dan varians dengan nilai 171,747.

Distribusi frekuensi dari variabel budaya organisasi diperoleh dari 169 sampel dapat diklasifikasikan dalam 9 kelompok. Kelas interval nilai tertinggi berada pada rentang 110-117 (33\%) kemudian diikuti oleh kelas interval 118-125 (18\%), sementara nilai paling kecil berada pada rentang 78-85 dan 142149 yaitu masing-masing sebesar $2 \%$. Data frekuensi dapat digambarkan sebagai berikut:

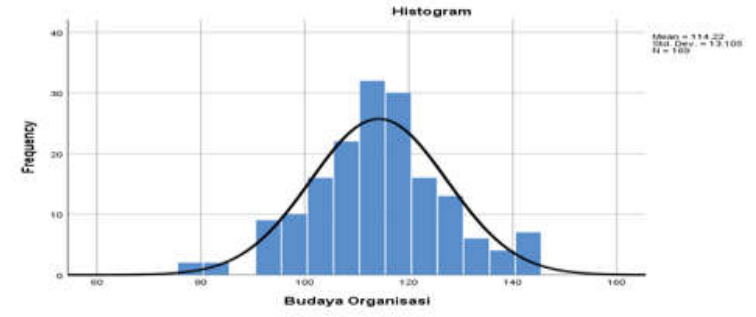

Gambar 3. Histogram Variabel Budaya Organisasi $\left(X_{2}\right)$

Uji normalitas data, uji homogenitas data dan uji kelinearan data adalah alat yang dipakai untuk menguji persyaratan analisis dalam penelitian ini.

Hasil perhitungan uji normalitas $X_{3}$ atas $X_{1}$ didapat nilai $D_{\max }=0.067$. Nilai tersebut lebih rendah dari nilai $D_{\text {tabel }}\left(n=169\right.$ dan $\alpha=0.05$ ) sebesar 0,104 , sehingga diperoleh nilai $D_{\max } M D_{\text {tabel }}$ maka $H_{0}$ diterima dan bisa diambil kesimpulan yaitu sebaran data profesionalisme guru atas kepemimpinan kepala sekolah berdistribusi normal.

Hasil perhitungan uji normalitas $X_{3}$ atas $X_{2}$ didapat nilai $D_{\max }=0.090$. Nilai tersebut lebih rendah dari nilai $D_{\text {tabel }}(n=169$ dan $\alpha=0.05)$ sebesar 0,104 , sehingga diperoleh nilai $D_{\text {max }} M D_{\text {tabel }}$ maka $H_{0}$ diterima dan bisa diambil kesimpulan yaitu sebaran data profesionalisme guru atas kepemimpinan kepala sekolah berdistribusi normal. 
Sedangkan hasil perhitungan uji normalitas $X_{2}$ atas $X_{1}$ didapat nilai $D_{\max }=0.088$. Nilai tersebut lebih rendah dari nilai $D_{\text {tabel }}(n=169$ dan $\alpha=0.05)$ sebesar 0,104 , sehingga diperoleh nilai $D_{\max } M$ $\mathrm{D}_{\text {tabel }}$ maka $\mathrm{H}_{0}$ diterima dan bisa diambil kesimpulan yaitu sebaran data profesionalisme guru atas kepemimpinan kepala sekolah berdistribusi normal.

Hasil perhitungan signifikansi dan linearitas regresi pada masing-masing pengaruh dimana hasil pengujian profesionalisme guru atas kepemimpinan kepala sekolah diatas diperoleh konstanta (a) sebesar 44,952 dan koefisien regresi $(b)=0,597$. Maka diperoleh persamaan regresinya yaitu $\hat{Y}=$ $44,952+0,597 X_{1}$

Pengujian signifikansi regresi profesionalisme guru $\left(\mathrm{X}_{3}\right)$ terhadap kepemimpinan kepala sekolah $\left(X_{1}\right)$ dinyatakan sangat signifikan. Pengujian linearitas regresi didapat dari nilai $F_{\text {hitung }}$ sebesar 0,837 sedangkan nilai $F_{\text {tabel }}$ pada tingkat kesalahan $\alpha(0,05)$ dengan $\mathrm{dk}$ pembilang 49 dan $\mathrm{dk}$ penyebut 118 yaitu 1,462 . Nilai $F_{\text {hitung }}(0,837) \mathrm{M} \mathrm{F}_{\text {tabel }}(1,462)$ maka bisa diketahui bahwa persamaan regresi profesionalisme guru terhadap kepemimpinan kepala sekolah ialah linear.

Hasil pengujian signifikansi profesionalisme guru terhadap budaya organisasi diatas diperoleh konstanta (a) sebesar 47,424 dan koefisien regresi $(b)=0,575$ dengan demikian diperoleh persamaan regresinya yaitu $\hat{Y}=47,424+0,575 X_{2^{\prime}}$ dapat dikatakan bahwa pengujian signifikansi regresi profesionalisme guru $\left(X_{3}\right)$ terhadap budaya organisasi $\left(X_{2}\right)$ didapat $F_{\text {hitung }}$ sebesar 70,378 . Nilai tersebut lebih besar jika dibandingkan dengan nilai $F_{\text {tabel }}$ pada $\alpha=0,05$ sebesar 3,05 sehingga persamaan regresi dinyatakan sangat signifikan. Pengujian linearitas regresi di dapatkan nilai $F_{\text {hitung }}$ sebesar 1,240 sedangkan nilai $F_{\text {tabel }}$ pada tingkat kesalahan $\alpha(0,05)$ dengan dk pembilang 46 dan $\mathrm{dk}$ penyebut 121 ialah 1,469 . Nilai $\mathrm{F}_{\text {hitung }}(1,240) \mathrm{MF}_{\text {tabel }}(1,469)$, oleh karena itu persamaan regresi profesionalisme guru terhadap budaya organisasi adalah linear.

Hasil pengujian persamaan regresi budaya organisasi terhadap kepemimpinan kepala sekolah diatas diperoleh konstanta (a) sebesar 70, 486 dan koefisien regresi $(b)=0,383$, maka diperoleh persamaan regresinya adalah $\hat{Y}=70,486+0,383 X_{1}$. dapat dikatakan bahwa pengujian signifikansi budaya organisasi $\left(X_{2}\right)$ terhadap kepemimpinan kepala sekolah $\left(X_{1}\right)$ didapat $F_{\text {hitung }}$ yaitu 34,589, nilai tersebut lebih besar jika dibandingkan dengan nilai $F_{\text {tabel }}$ pada $\alpha=0,05$ yaitu 3,05 maka persamaan regresi dinyatakan sangat signifikan. Pengujian linearitas regresi budaya organisasi atas kepemimpinan kepala sekolah adalah linear.

Hasil perhitungan koefisiensi jalur didapatkan bahwa kepemimpinan kepala sekolah $\left(X_{1}\right)$ berpengaruh langsung positif pada Profesionalisme $G u r u\left(X_{3}\right)$. Sedangkan koefisiensi determinasi dari tabel terlihat $R_{\text {square }}=0,374$ yang mempunyai arti yaitu $37,4 \%$ profesionalisme guru dapat dijelaskan dengan kepemimpinan kepala sekolah.

Hipotesis kedua terdapat pengaruh langsung budaya organisasi $\left(X_{2}\right)$ terhadap profesionalisme guru $\left(\mathrm{X}_{3}\right)$, bisa diambil kesimpulan yaitu budaya organisasi $\left(\mathrm{X}_{2}\right)$ berpengaruh langsung positif terhadap profesionalisme guru $\left(X_{3}\right)$. Koefisien determinasi dari tabel terlihat $R_{\text {square }}=0,296$ yang mempunyai arti yaitu 29,6\% profesionalisme guru bisa dijelaskan dengan budaya organisasi.

Hipotesis ketiga terdapat pengaruh langsung Kepemimpinan Kepala Sekolah $\left(X_{1}\right)$ terhadap Budaya Organisasi $\left(X_{2}\right)$. Sehingga bisa diambil kesimpulan yaitu kepemimpinan kepala sekolah $\left(X_{1}\right)$ berpengaruh langsung positif terhadap budaya organisasi $\left(\mathrm{X}_{2}\right)$. Koefisien determinasi dari tabel terlihat $R_{\text {square }}=0,172$ yang mempunyai arti yaitu $17,2 \%$ budaya organisasi dapat dijelaskan dengan kepemimpinan kepala sekolah.

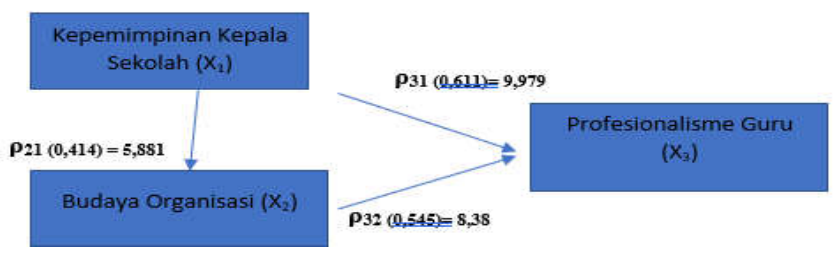

Gambar 4. Diagram Konstelasi Permasalahan Penelitian

Melalui hasil perhitungan hipotesis pertama bisa dibuktikan bahwa terdapat pengaruh langsung antara kepemimpinan kepala sekolah terhadap profesionalisme guru. Hasil perhitungan diperoleh nilai signifikansi 0,000 lebih kecil dari 0,05 dan nilai $t_{\text {hitung }}$ sebesar 9,979 lebih besar dari $t_{\text {tabel }}$ 1,65 
yang bermakna bahwa hipotesis penelitian menerima $\mathrm{H}_{1}$. Hasil pengujian diperoleh nilai koefisien pengaruh sebesar 0,611.

Kepala sekolah harus memiliki kemampuan dan kesiapan dalam mempengaruhi, mendorong dan menggerakkan guru untuk bekerja secara profesional. Aktivitas yang dikerjakan oleh guru dalam konteks pembelajaran yang sesuai dengan wewenang dan kewajibannya disebut profesionalisme guru. Profesionalisme guru mempunyai hubungan erat dengan kepemimpinan kepala sekolah sebagai dasar dan penggerak seseorang memilih profesi sebagai guru, dengan demikian kualitas profesionalisme guru dipengaruhi oleh kepemimpinan kepala sekolah yang kuat terutama di masa pandemi Covid-19.

Pengujian hipotesis kedua membuktikan budaya organisasi mempunyai pengaruh langsung positif terhadap profesionalisme guru. Melalui hasil pengujian didapat nilai koefisien pengaruh sebesar 0,545. Hasil perhitungan diperoleh nilai signifikansi 0,000 lebih kecil dari 0,05 sementara nilai $t_{\text {hitung }}$ sebesar 8,389 lebih besar dari 1,65 yang berarti bahwa hipotesis $\mathrm{H}_{1}$ diterima. Pada hasil perhitungan hipotesis kedua dapat dibuktikan yaitu terdapat pengaruh langsung budaya organisasi terhadap profesionalisme guru.

Guru profesional bisa juga disebut sebagai seorang guru yang mempunyai kompetensi dan keahlian khusus dalam bidang keguruan baik materi maupun metode sehingga dapat melaksanakan tugas dan fungsinya dengan kemampuan yang maksimal. Oleh karena itu dalam kondisi pandemik ini guru dituntut untuk menjaga profesionalismenya dalam mengajar online. Profesionalisme guru dengan kata lain dipengaruhi oleh budaya organisasi yang baik.

Pengujian hipotesis ketiga bisa dilihat bahwa kepemimpinan kepala sekolah berpengaruh langsung positif terhadap budaya organisasi. Dari hasil pengujian diperoleh nilai koefisien pengaruh sebesar 0,414 . Hasil perhitungan diperoleh nilai signifikansi 0,000 lebih kecil dari 0,05 dan nilai $t_{\text {hitung }}$ sebesar 5,881 lebih besar dari 1,65 yang berarti bahwa menerima $\mathrm{H}_{1}$. Dari hasil perhitungan hipotesis ketiga dapat dibuktikan bahwa terdapat pengaruh langsung antara kepemimpinan kepala sekolah terhadap budaya organisasi.

Kepala sekolah bisa disebut memimpin dengan baik dalam menyelenggarakan pendidikan bila kepala sekolah tersebut memahami peran dan fungsinya. Hasil penelitian ini mendukung penelitian yang dilaksanakan oleh Keizer dkk (De Keizer \& Pringgabayu, 2018: 14-25) yang memberikan kesimpulan yaitu terdapat pengaruh yang signifikan antara kepemimpinan kepala sekolah terhadap budaya organisasi.

\section{SIMPULAN DAN SARAN}

Kepala sekolah harus selalu meningkatkan kemampuannya didalam memimpin agar dapat memberikan pengaruh positif, mendidik serta memotivasi guru agar dapat meningkatkan profesionalisme guru. Untuk meningkatkan profesionalisme guru, kepala sekolah juga perlu menyusun program sekolah tentang pembinaan dan pengembangan profesi guru. Kepala sekolah harus berupaya untuk terus meningkatkan budaya organisasi yang kondusif dengan membangun etos kerja yang efektif dan efisien khususnya yang berkaitan dengan kinerja guru.

Peningkatan profesionalisme guru perlu memperhatikan faktor budaya organisasi sekolah melalui tindakan nyata seperti mentaati dan melaksanakan ketentuan jam kerja, melaksanakan tugas dengan baik dan bertanggung jawab, mengembangkan nilai-nilai budaya organisasi yang positif disekolah dan mengembangkan perilaku budaya kerja dan budaya disiplin di lingkungan sekolah.

\section{PUSTAKA ACUAN}

Anwar, M. (2018). Menjadi guru profesional. Prenada Media.

Dagli, A., \& Akyol, Z. (2019). The Relationship between Favouritism Behaviours of Secondary School Administrators and Organizational Commitment of the Teachers. Journal of Education and Training Studies, 7(7), 35-49.

De Keizer, H., \& Pringgabayu, D. (2018). Pengaruh Kepemimpinan Kepala Sekolah, Motivasi, dan Budaya Sekolah, Terhadap Kinerja Guru Di SMK ICB Cinta Niaga Kota Bandung. JMBI UNSRAT (Jurnal Ilmiah Manajemen Bisnis Dan Inovasi Universitas Sam Ratulangi)., 4(1). Dosen, T. (2008). Administrasi Pendidikan Universitas Pendidikan Indonesia. Manajemen Pendidikan.

Ismail, T. (2017). Kepemimpinan, kompensasi, motivasi kerja, dan kinerja guru SD negeri. Jurnal Administrasi Pendidikan UPI, 24(1), 60-69. Kunandar. (2011). Guru Profesional. Rajawali Press.

Undang-Undang RI No. 14 Tahun 2005 Tentang Guru dan Dosen. Jakarta: RI K.P.N, 2019 